\title{
ESTUÁRIO, PAISAGEM-FLUXO DE PESCADORES ARTESANAIS
}

\author{
Pedro Castelo Branco Silveira ${ }^{1}$ \\ Beatriz Mesquita ${ }^{2}$ \\ Luciana Melo ${ }^{3}$ \\ Ivson Oliveira Filho ${ }^{4}$
}

Este artigo trata da constituição de uma paisagem estuarina. A paisagem que aqui nos interessa se constitui a partir das disputas socioecológicas referentes ao reconhecimento da atividade de pesca artesanal no estuário do Rio Goiana, nos estados de Pernambuco e Paraíba.

Partimos de uma ideia, já explorada anteriormente (Silveira, 2009; 2011), de que paisagens são produto do ato de habitar (Ingold, 2000). Constituir uma paisagem, portanto, implica a constituição de uma malha de relações entre humanos e não humanos, sendo os fios desta malha os movimentos e percursos percorridos. Descreveremos a constituição desta paisagem por uma tensão entre forças produtivas de espaços lisos e de espaços estriados (Deleuze e Guatarrí, 2002 [1980]), ou seja, entre devires de fluidez e plasticidade (fluxos de marés, de pescados e de pescadores), por um lado, e devires de fixidez e disciplinamento (ordenamentos territoriais, instalação de empreendimentos privados), por outro. Por meio deste tipo de abordagem podemos ter uma aproximação menos formalista das lutas territoriais dos pescadores artesanais ${ }^{5}$.

\section{A paisagem-fluxo do estuário do Rio Goiana}

O Rio Goiana vem do Agreste pernambucano, passa pela cidade de Goiana e desenvolve um trajeto sinuoso quando chega próximo à sua foz, imerso na vegetação de manguezais que forma um conjunto de ilhas e canais de água de salinidade variável, sob influência marinha, que mudam de feição conforme o subir e descer das marés. As marés, por sua vez, variam de forma diferenciada ao longo do ciclo lunar e ao longo do ano.

\footnotetext{
${ }^{1}$ Fundação Joaquim Nabuco, Recife, Brasil.

${ }^{2}$ Fundação Joaquim Nabuco, Recife, Brasil.

${ }^{3}$ Instituto Piagaçu, Manaus, Brasil..

${ }^{4}$ Universidade Federal de Pernambuco, Recife, Brasil.

5 O substrato empírico deste artigo está na pesquisa etnográfica empreendida nos projetos "Reservas extrativistas e pesca artesanal: etnografia do campo socioambiental em Pernambuco" (2008-2009) e "Dinâmicas ecológicas em ambientes estuarinos no Nordeste brasileiro" (2007-2011), desenvolvidas na Fundação Joaquim Nabuco.
} 
O movimento das marés, bem conhecido por marujos, pescadores, surfistas, biólogos marinhos e quaisquer pessoas que desenvolvem atividades na interseção entre o mar e a terra, é fundamental, nas zonas estuarinas, para os movimentos vitais dos seres aquáticos que as habitam. A entrada de peixes marinhos no estuário, a reprodução de moluscos bivalves, o ciclo de atividade de caranguejos, entre outros, tem uma íntima relação com o movimento das marés. Viver em contato com dinâmicas estuarinas parece implicar, portanto, alguma modalidade de relação com os fluxos de água doce e salgada que constituem a conexão entre rio, mar e terra.

É das conexões e movimentos relativos às paisagens da pesca artesanal que nos ocupamos aqui. Para isso, nos é útil uma tríade de categorias operadas pelas pessoas que pescam neste estuário, os termos pescador, pescaria e pescado. ${ }^{6}$ Ramalho (2012) registra os comentários de alguns pescadores do litoral pernambucano a este respeito:

\begin{abstract}
“Os peixes estão na água e tem que saber usar a armadilha certinha pra ele, naquela pescaria correta; e o pescador é o cara que sabe disso. É uma continuidade dos pescadores velhos pros novos essa sabedoria”.

"As pescarias como a dos peixes cavala, cioba, e do camarão, exigem um cara, um pescador próprio pra elas, pra matar esses pescados. Quer saber como é um pescador? Olha a pescaria dele".

"Pescaria é um tudo na pesca, e é ela que liga o pescador ao peixe na luta pra viver"

“O pescador só vai pra onde tem pescado, mas ele tem que saber que pescaria usar pra isso. É um triângulo. Um triângulo onde a pescaria é o mais frontal, o peso maior das coisas"

“Quem já viu pescador sem ter e praticar pescaria?! É com a pescaria que a gente vira... que a gente é pescador, porque é ela quem faz com que os pescados sejam pegos por nós".
\end{abstract}

Entendemos a categoria Pescado como um termo que designa um peixe-emrelação, ou seja, o organismo aquático que contém características (affordances, no dizer de Ingold, 2000) que os torna pescáveis. A pescaria é a ação experiencial que transforma organismo humano em pescador e organismo aquático em pescado. Consiste numa atividade, num conjunto de ações, bem como num conjunto de técnicas e um conjunto de conhecimentos associados. São práticas de conhecimento (Law e Mol, 2002). É a pescaria, enfim, que produz o pescador e o pescado. Diferentes modalidades

\footnotetext{
${ }^{6}$ Estas categorias nos foram primeiramente apresentadas pelo colega Cristiano Ramalho, a partir de sua excelente pesquisa entre os pescadores de Carne de Vaca, no estuário do Rio Goiana, e de São José da Coroa Grande, no Litoral Sul de Pernambuco (Ramalho, 2012). Ramalho as analisou em um referencial marxista, como análogo à tríade trabalhador-trabalho-natureza. Fazemos aqui uma outra apropriação destas categorias nativas, a partir de outro referencial teórico.
} 
de pescarias, portanto, produzem diferentes pescadores (Sautchuk, 2007). O pescador é, portanto, para além de uma noção identitária, um humano-em-relação na rede conformada pela pesca artesanal, ou seja, aquele humano que captura e conhece o pescado valendo-se de uma pescaria. Há, no estuário do Rio Goiana, diversas modalidades de relação pescador-pescaria-pescado. Indicaremos, a seguir, de forma não exaustiva, aspectos destas modalidades.

Os pescadores do Rio Goiana residem principalmente em cinco localidades: o núcleo urbano de Goiana, em especial o bairro de Baldo do Rio; o pequeno município paraibano de Caaporã, que margeia o rio antes deste chegar definitivamente ao mar; o povoado de São Lourenço, pertencente ao município de Goiana, na margem pernambucana; e na foz propriamente dita, temos na margem esquerda Acaú, povoado pertencente ao município paraibano de Pitimbu; e na margem direita Carne de Vaca, que pertence a Goiana.

Os pescadores de Baldo do Rio deslocam-se rio abaixo em pequenas embarcações tripuladas, chamadas caícos, utilizando o Porto de Gongaçari e outros portos no caminho. Pescam peixes estuarinos com redes, sejam as de camboa, que se aproveitam da variação da maré e dos movimentos de entrada e saída dos peixes dos braços dos rios (as camboas), sejam as redes de caçoeira, de fundo, que emalham os peixes atravessando um canal principal. A pesca de camarão já foi muito importante para os pescadores de Baldo do Rio, que era realizada de forma simples utilizando-se redes ou pequenos balaios (jererés) com iscas, mas hoje os camarões estuarinos são muito menos abundantes. Há também na cidade de Goiana catadores de caranguejos que utilizam-se do estuário, deslocando-se com pequenas canoas até uma certa região do mangue e lá coletando os crustáceos. Os pescadores do município de Caaporã também pescam no estuário, se utilizando do porto de Gongaçari. Há também muitos catadores de caranguejo em Caaporã.

São Lourenço fica já próxima à desembocadura do estuário, às margens do rio Megaó, último grande afluente do rio Goiana antes da foz. Do alto da vila vê-se o manguezal abaixo, cercado por canavial. Para acessar o rio Megaó de São Lourenço desce-se uma íngreme trilha e alcança-se o porto, formado por uma grossa camada de conchas de mariscos. Considerada a localidade mais pobre do estuário do rio Goiana, há lá um número grande de catadores de caranguejos e aratus, e também de marisqueiras, que se utilizam dos mesmos bancos de mariscos (croas) usados pelos catadores de Carne de Vaca e Acaú. A prática da mariscagem, tendo como principal alvo o marisco 
pedra (Anomalocardia brasiliana) é desenvolvida tanto na praia de Carne de Vaca como também em bancos de areia no estuário chamada Ilha dos Cachorros (croa localizada na desembocadura dos rios Goiana e Megaó). Além do marisco coleta-se ostra, sururu e caranguejo.

Carne de Vaca e Acaú localizam-se na foz do rio Goiana, a primeira do lado pernambucano, a segunda do lado paraibano. São praias que tiveram grande influência da especulação imobiliária, tendo um número grande de casas de veraneio. Em Carne de Vaca há, além da catação de marisco, em menor escala, a catação de caranguejos, aratus, guaiamuns e a pesca de peixes e camarões no estuário. Em Carne de Vaca, entretanto, é bem importante a pesca de peixes no mar de dentro, área marinha próxima à praia, delimitada pelos arrecifes de corais. Em Acaú uma atividade pesqueira de grande importância econômica é a pesca da lagosta, realizada em alto mar por homens embarcados por até 10 dias.

Além dos pescadores que vivem nas localidades citadas, utilizam-se também do estuário do rio Goiana catadores de caranguejo e marisco de outras regiões do litoral pernambucano. Isso se dá de forma mais acentuada no período em que os caranguejosuçá encontram-se vulneráveis à captura ao saírem para reproduzir, o chamado período da andada, que ocorre no primeiro trimestre do ano. Apesar de ser um período em que os pescadores da região tradicionalmente coletam os caranguejos, durante a andada a captura de caranguejos é proibida por lei, proibição esta que tem defensores e opositores dentre os pescadores.

\section{Mariscos}

Vejamos primeiro o trabalho das marisqueiras, presentes em Acaú, São Lourenço e Carne de Vaca. Ao chegarmos à foz do rio Goiana em horário de maré baixa, veremos uma série de pessoas paradas sobre as croas, dentro da água, revolvendo o sedimento, seja com as mãos, com o auxílio de uma colher ou outros instrumentos. O provável sol quente é resolvido com o uso de bonés e panos amarrados na cabeça. É uma atividade de paciência que dura turnos de 5 ou 6 horas, realizada principalmente por mulheres, muitas vezes com a ajuda das crianças mais velhas, que, após a subida da maré, levarão o produto de sua coleta para beneficiar em casa, o que envolve outro tipo de trabalho.

O beneficiamento ocorre em duas etapas, o cozimento e o debulhamento. Ambos duram em média dez minutos para cada dez quilos de mariscos brutos (com conchas) 
coletados. Depois de debulhados, os 10 quilos dos moluscos são pesados e empacotados para a comercialização. Observamos em campo que apenas 800 gramas de carne são revertidas para cada $10 \mathrm{~kg}$ de mariscos debulhados. $\mathrm{O}$ valor cobrado por quilo do molusco é variável de acordo com o período, podendo durante o verão ser três vezes mais caro que no inverno.

O principal molusco coletado é o marisco-pedra (Anomalocardia brasiliana), que ocorre na foz de estuários, desde o Caribe até o sul do Brasil. De hábito alimentar filtrador, vive enterrado nos primeiros centímetros de bancos de areia em profundidades de 0,5 a 1,5 metro . O marisco-pedra reproduz-se uma vez por ano e é sensível às variações de temperatura e às chuvas, que provocam mudanças na salinidade (SilvaCavalcanti, 2011).

O termo marisqueira é utilizado no feminino, mas é comum atualmente vermos muitos homens nesta prática. A mariscagem e a catação de caranguejos são considerados entre as pescarias como a de menor status social. Se a catação de caranguejos é historicamente realizada por pessoas pobres de ambos os sexos, a mariscagem é historicamente tarefa feminina. Há catadores de caranguejo e marisqueiras que desenvolvem a atividade com orgulho profissional e em tempo integral. Muitas marisqueiras e catadores de caranguejo, pelo baixo status social da profissão e o baixo retorno econômico, entretanto, afirmam que desenvolvem a profissão por falta de opção.

Como é tarefa que requer pouco subsídio tecnológico e relativamente simples de se aprender, é utilizada também como alternativa econômica de pessoas que não se consideram profissionais da pesca. Ou seja, na falta de recursos, vai-se para a maré. Assim explica-se a existência de muitos homens no trabalho da mariscagem em Acaú e Carne de Vaca, atualmente. Em ambas as localidades há ocupações urbanas precárias, recentes, de áreas de manguezal, em que convivem moradores mais empobrecidos das famílias da região com migrantes de áreas urbanas, especialmente da periferia de Goiana. Em Acaú este tipo de ocupação precária é mais evidente, com o crescimento da chamada Rua do Povo, com características de favela urbana.

Dessa forma, há uma grande heterogeneidade presente mesmo na pescaria de mariscos. Essa heterogeneidade reflete-se em disputas pela definição de pertencimento à categoria marisqueira e também ao debate sobre a adequação das técnicas utilizadas. É consenso a afirmação de que hoje há muito mais marisqueiras do que há algum tempo atrás. Silva-Cavalcanti (2011), em 165 entrevistas com marisqueiras em Acaú e Carne 
de Vaca, encontrou $82,4 \%$ de mulheres na atividade e $17,6 \%$ de homens. Metade das mulheres declarou ter aprendido a atividade com as próprias mães, enquanto crianças, enquanto menos de $10 \%$ dos homens declarou ter aprendido as técnicas de mariscagem na família.

As técnicas antigas de mariscagem presumem o uso apenas das mãos ou de uma colher ou instrumento semelhante. Os mariscos são inspecionados a cada captura e dispensam-se os que tem tamanho considerado menor que o adequado. O motivo desta dispensa pode estar numa estimativa de rendimento de carne em função do volume e peso de concha, bem como numa atitude deliberadamente conservacionista, partindo-se do princípio que aqueles mariscos menores precisam crescer para serem futuramente capturados. Silva-Cavalcanti (2011) afirma que 46\% das marisqueiras entrevistadas em Acaú e Carne de Vaca utilizam apenas as mãos na cata de mariscos.

Atualmente muitas das marisqueiras, em especial aquelas que realizam a atividade de forma mais esporádica, usam técnicas consideradas inadequadas pelas próprias marisqueiras. Essas técnicas consistem no uso de instrumentos também simples como puçás, grades, telas metálicas, enxadas ou caixas para revolver e peneirar o substrato. Com o uso destes equipamentos, afirmam algumas marisqueiras, os mariscos pequenos são quebrados e os mariscos recusados na seleção são descartados a posteriori, vindo a morrer.

\section{Lagostas}

Contrastando com a mariscagem, que supõe permanência na croa e é compativel com afazeres domésticos, sendo considerado trabalho feminino e de baixo status social, há a pesca de lagosta, que dentre as localidades estudadas no estuário do rio Goiana é desenvolvida apenas em Acaú, e, da forma como é feita hoje, é atividade relativamente recente. É uma atividade de alto mar. Até alguns anos atrás, os pescadores de Acaú não dispunham de embarcações que os levassem a grandes distâncias em mar aberto, como é o caso dos pescadores de Carne de Vaca.

As lagostas vermelha (Panulirus argus) e cabo verde (Panulirus laevicauda) são as espécies de lagosta mais capturadas no Brasil. Quando jovens, são encontradas nas formações bênticas do infralitoral, habitando as regiões já próximas ao estuário. As lagostas adultas, por sua vez, vivem a profundidades médias de 40 metros, encontrando abrigo nos fundos de algas calcárias vermelhas, onde permanecem entocadas durante o 
dia. No início da noite os indivíduos se dispersam pelos bancos de algas calcárias vermelhas e verdes. São carnívoras, consumindo animais marinhos sésseis ou com movimentos limitados, e são gregárias, formando grandes agrupamentos.(Ivo e Pereira, 1996)

A pesca da lagosta é uma das modalidades mais conflituosas de pesca $\operatorname{artesanal}^{7} \mathrm{~A}$ pesca comercial da lagosta no Brasil se desenvolveu a partir dos anos de 1960, com incentivos governamentais da Superintendência de Desenvolvimento da Pesca (Sudepe). Nos anos 60 e 70 criaram-se diversas empresas de pesca de lagosta, localizadas principalmente no Ceará. Dos anos de 1970 a 1990, devido à sobrepesca, os estoques de lagosta no Ceará rapidamente decaíram e as empresas se endividaram. Foi então a partir dos anos de 1980 que a grande frota lagosteira cearense passou a procurar outros estados do Brasil para realizar a atividade. Foi assim que, nos anos de 1990, instalou-se em Acaú uma frota de barcos lagosteiros provenientes do Ceará, que passou a incorporar tripulações de jovens pescadores locais.

A lagosta era inicialmente pescada, no Ceará, utilizando-se um petrecho chamado manzuá ou covo, que consiste numa armadilha retangular de madeira, bambu ou revestida com tela. Antes mesmo do covo utilizou-se no Ceará como armadilha o jereré, cujo princípio de captura é o mesmo. Os covos são lançados à noite em uma área propícia à pesca de lagostas adultas, cada covo com uma isca. As lagostas penetram na armadilha e não são capazes de sair. É um método seletivo de tamanho e que captura o animal vivo, prestando-se ao retorno do animal ao mar, se for uma fêmea ovada, por exemplo.

Com a sobrepesca, as empresas, pressionadas pelo alto custo fixo de produção em decadência, principalmente se considerarmos o alto custo de sua frota, formada em sua maioria por grandes barcos, passaram a adquirir a lagosta de terceiros e abandonaram os grandes barcos super dimensionados. Essa nova frota foi composta por barcos de madeira de menor porte e posteriormente por jangadas (apenas no Ceará e Rio Grande do Norte) pertencentes aos pescadores artesanais.

As quase falidas empresas de pesca de lagosta focaram-se então no beneficiamento e exportação da lagosta, estimulando a pesca ilegal, porém sem envolvimento direto na captura. Além de repassar o risco da captura para a pesca

\footnotetext{
${ }^{7}$ Dependendo do conceito de pesca artesanal utilizado, a pesca da lagosta, operada por relações patrão-empregado, pode até não ser considerado como tal. No contexto estudado os pescadores de lagosta consideram-se pescadores artesanais.
} 
artesanal, a indústria não sobreviveria economicamente se continuasse capturando visto o alto custo fixo com o pagamento dos pescadores, os quais eram empregados formais. Os barcos da pesca artesanal são capazes de praticar baixíssimos custos de produção e ainda utilizam o sistema de parceria, onde os pescadores recebem partes do faturamento da pescaria, dividindo o lucro, mas também o prejuízo com o dono do barco.

Além de modificarem a profundidade da pescaria, cada vez mais perto do litoral incidindo sobre espécimes mais jovens, essa nova frota passou a utilizar covos menos seletivos, impactando ainda mais as populações de lagostas. Daí passaram a utilizar redes de caçoeira ao invés dos covos. Este mostrou-se um método mais eficiente a curto prazo, mas altamente impactante: as redes varrem e destroem todo os substrato onde vivem as lagostas, destruindo seu habitat e capturando animais de todos os tamanhos, muitas vezes já mortos. Pressionado pelos pescadores e apesar dos protestos de ambientalistas, o Governo Federal liberou o uso desta técnica por alguns anos. Paralela ao uso de redes de caçoeira, uma terceira técnica de captura de lagostas passou a ser utilizada, o mergulho. Para se capturar lagostas mergulhando, mantem-se um compressor no barco fornecendo ar a um pescador ligado a ele por um tubo. O mergulhador desce, durante o dia, dezenas de metros e captura facilmente os animais em suas locas, seja com o auxílio de um arpão, seja com o uso de uma pequena rede. A pesca de lagosta por mergulho é também considerada altamente predatória. Além do impacto ambiental, a pesca de mergulho mostrou-se devastadora para a saúde dos pescadores. O mergulho em profundidade sem o uso de técnicas adequadas de descompressão causou e tem causado mortes e invalidez em centenas de pescadores, o que faz com que tal técnica passe a ser temida entre os lagosteiros.

Já nos anos 2000 formou-se em nível federal um Comitê Gestor da Lagosta, que proibiu novamente o uso de redes e compressores, por meio de uma desastrosa política que indenizou os lagosteiros pelas redes e compressores recolhidos, mas não teve uma posterior contrapartida eficiente de fiscalização e de diálogo. O resultado foi que as indenizações serviram para os pescadores de lagosta renovarem seus equipamentos de pesca proibida.

Tentando mitigar a tragédia da lagosta que ele mesmo incentivara, o Estado brasileiro procura, com pouco sucesso, controlar sua pesca. Além da tripulação portar carteira de pescador, hoje os barcos lagosteiros precisam ter uma autorização para operar. Há desde os anos de 1990 o defeso da lagosta, chegando até a durar seis meses (dezembro a maio), período em que a pesca é proibida os pescadores autorizados 
recebem um seguro-defeso.

O estuário do Rio Goiana ficou à margem do processo de pesca comercial da lagosta até os anos de 1990. Havia, portanto, na linguagem da engenharia de pesca, um grande estoque de lagosta quase que inexplorado na região do estuário do rio Goiana que, junto com o canal de Santa Cruz, é considerada legalmente uma das mais importantes áreas criatórias de lagosta do país.

Até alguns anos atrás lagostas eram capturadas em Acaú apenas em pequenas quantidades, em geral indivíduos jovens que habitavam o estuário ou o mar de dentro. Apareciam como fauna acompanhante dos pescados de maior interesse, e não eram exploradas como recurso pesqueiro de alto valor. Assim conta uma antiga marisqueira de Acaú, de 84 anos:

\begin{abstract}
Papai ia pra maré. A gente tudo garota, tudo já moça. Papai ia pra maré, quando vinha arriava aqueles balaios grandes, cheio de peixe, camarão e lagosta. As lagostas saiam pulando, pra detrás: Pá, pá, pá, pá! Porque elas batem, quando se arriam [os balaios] elas saem. Agora, eram aqueles camarões brancos grandes e as lagostas saltando. Papai enchia um cesto todo de lagosta, e naquele tempo se chamava lagostinho. (...) A gente chamava "Olha o lagostinho!", A gente fazia aquela festa, rodeávamos... Quando papai chegava da maré, à boca da noite, ou maré da manhã, a gente rodeava, ia pegar... Aquilo ali papai dava ao povo. Era. Aquelas lagostas, aqueles lagostinhos todos, papai dava. Dividia com os pescadores e dava às pessoas que chegavam.
\end{abstract}

Os pescadores de Acaú tinham como atividade até então da pesca estuarina e no mar de dentro, pescando peixes e camarões. Antes de haver uma frota de barcos lagosteiros sediada em Acaú, havia na região a presença de barcos cearenses e de empresas sediadas no Recife que circulavam pelo litoral pernambucano. Isso porque os barcos lagosteiros percorrem grandes distâncias para realizar pescarias. Só nos anos de 1990 instalou-se em Acaú uma frota de barcos lagosteiros provenientes do Ceará, que passou a incorporar tripulações de jovens pescadores locais.

A abundância e altos lucros trazidos pela lagosta, em comparação com outras formas de pescado, eram ostentados pelos pescadores recém-inseridos na região. Com o tempo mais barcos entraram na região, outros foram construídos, inclusive com financiamento do Banco do Nordeste. O porto de Acaú permitia boa logística para os barcos, a fiscalização do Ibama na Paraíba era mais branda que em Pernambuco e a atividade tornou-se tão importante economicamente que passou a ser protegida pelo poder municipal.

Assim, a pesca de lagosta chegou a Acaú em um momento de crise no setor, já 
utilizando a rede e o compressor, métodos considerados predatórios. Os ganhos acima da média, o uso de equipamentos e técnicas proibidas e os conflitos com o poder público deram à atividade um ar de clandestinidade, que é sentido ao se chegar a Acaú. Os pescadores de lagosta são, de fato, desconfiados para conversas com pesquisadores. Vêem-se ainda na comunidade vários pescadores com problemas de saúde pelo uso de compressor. As lagostas eram compradas principalmente por três empresas de Recife, uma delas com uma sede em Acaú.

\section{Peixes}

Os pescadores de Baldo do Rio e de Caaporã mas também de Carne de Vaca e Acaú desenvolvem pesca de peixes estuarinos como o camorim (Centropomus undecimalis e C. parallelus), a tainha (Mugil curema valenciennes), a saúna (Mugil liza) e a carapeba (Eucinostomus argenteus e outras espécies). Pesca-se também, em menor escala, camarões. Em Baldo do Rio, os pescadores se deslocam rio abaixo, com paradas no caminho, até o porto de Gongaçari. Existem diversos pontos de pesca, onde se colocam redes de camboa, que capturam os peixes que se deslocam das reentrâncias do rio para o leito principal, e as redes de caçoeira, que fecham a boca do rio. As redes de caçoeira são um ponto polêmico entre os pescadores de Baldo do Rio, pois além de serem consideradas mais predatórias, hoje são colocadas em caráter competitivo pelos pescadores, sem uma postura de respeito a quem armou sua rede primeiro.

Em Carne de Vaca há ainda a pesca realizada sobre a plataforma continental que sofre influência das águas férteis derramadas pelo rio que chega ao mar, ou seja, no mar de dentro. Utilizam-se técnicas semelhantes às da pesca estuarina, com trabalho cooperativo entre parentes ou amigos, em geral um deles o dono da canoa. Passam de 4 a 8 horas por dia no mar e vendem sua produção no mercado local. O período mais propício é o verão, quando a água do mar fica menos turva. No inverno pesca-se de linha como complemento à pesca de redes, capturando pescados em pontos de pesca conhecidos, além de se ir a outras praias onde a pesca esteja melhor (Ramalho, 2012).

\section{Caranguejos}

A captura de caranguejo-uçá (Ucides cordatus) tem como método tradicional a coleta manual, sem o uso de qualquer ferramenta. A movimentação dos catadores de 
caranguejo-uçá pelos manguezais, enterrando seus braços na lama, apesar de exigir uma refinada sinergia com os fluxos das marés, desde sempre conferiu a estes um baixíssimo status social. A captura dos guaiamuns (Cardisoma guanhumi), que fazem tocas "limpas" dentro da lama do mangue, e podem ser alimentados em casa com vegetais frescos para melhorar o sabor de sua carne, ou a coleta dos aratus (Goniopsis cruentata) que, diferente dos uçás, habitam as copas das árvores dos mangues, consistiam, durante o século XX, em atividades complementares à coleta do caranguejo-uçá.

Os catadores de caranguejo de Goiana, Caaporã e São Lourenço, no estuário do Rio Goiana, são em grande número, e difíceis de estimar. De forma geral vivem em situação de grande pobreza, raramente se articulam com colônias, associações e outras entidades representativas dos pescadores e dessa forma não aparecem nos quadros de suas diretorias. Muitos transitam entre a ocupação do mangue e outras ocupações do trabalho informal urbano. Como afirmou uma liderança dos pescadores da região, "a maré não diz 'não há vagas' ".

Nos anos de 1990, coincidindo com a implantação de projetos de carcinicultura no litoral nordestino, uma grande epidemia viral dizimou a população de caranguejos-uçá de uma vasta área da costa nordestina, incluindo Pernambuco. Os catadores de caranguejo, já prejudicados no acesso ao mangue em diversas regiões onde a carcinicultura foi implantada, tiveram, com a epidemia, que parar a atividade ou passar a explorar outros crustáceos aparentados do caranguejo. Assim aumentou a pressão sobre a coleta do siri (Callinectes sp.), do guaiamum e do aratu , que são capturados com técnicas ligeiramente diferentes da do caranguejo-uçá. No período da pesquisa, encontrava-se no porto de São Lourenço basicamente desembarque de aratu, além do marisco.

Em 2010 a população do caranguejo-uçá começava a se restabelecer no estuário do rio Goiana. Mas uma nova questão se colocava, que trazia também os catadores de caranguejo para uma condição de marginalidade: a introdução da redinha, uma inovação predatória na técnica de captura do caranguejo-uçá. Nos anos de 1990, também coincidindo com a doença do caranguejo-uçá, a redinha foi sendo adotada em grande parte do litoral nordestino. Esse método consiste no uso de um emaranhado de finos fios de náilon ou plástico obtido de sacolas comuns. Na maré seca essas armadilhas são postas nas entradas de muitas tocas de caranguejo. Por possuírem muitas saliências, articulações simples e membros rígidos, os caranguejos se aprisionam nestes entrelaçados de fios no momento em que saem das suas tocas ou desejam retornar a 
elas.

Como o tamanho dos caranguejos entocados não é sabido, muitos dos capturados não são aptos à comercialização e consumo. Muitos caranguejos são capturados mas não são recolhidos, quando o trabalho do catador atrasa e a maré sobe antes do fim do trabalho. Os caranguejos que foram abandonados presos morrem e as redinhas que não foram recolhidas ficam soltas no ambiente recapturando caranguejos e aumentando a incidência de mortes.

Atualmente é muito difícil encontrar um catador de caranguejo no rio Goiana, e no litoral pernambucano em geral, que use o método tradicional. Os catadores de caranguejo usuários da redinha colocam-se em condição de clandestinidade, usando uma técnica proibida pelo órgãos ambientais e considerada muito predatória entre os próprios pescadores. Ao lado disso, não havia, no período da pesquisa, qualquer tipo de política pública para catadores de caranguejo, para além da proibição da captura (defeso) no período da reprodução. Os movimentos dos catadores de caranguejos pelos mangues do rio Goiana estão presentes em toda parte, mas são silenciosos e silenciados, invisíveis e invisibilizados, marginais e marginalizados.

\section{Paisagem}

Cada pescaria implica diferentes movimentos no estuário, movimentos estes que incluem a movimentação do pescador das áreas de moradia até as áreas de pesca e também os movimentos de procura e captura do pescado. Esses movimentos estão conectados com a forma de habitar do pescado em questão (seus ritmos, hábitos e horários) e com os fluxos de água doce e salgada, ou seja, as mudanças no nível da água sobre a lama, sobre as croas e sobre a vegetação de mangue, além da modificação da salinidade ao longo do curso do rio próximo à foz. Por causa disso, por exemplo, o horário de ir para a maré é de fundamental importância para todas as pescarias.

Há, porém inúmeras especificidades de cada modalidade de pescaria. Para os caranguejeiros é importante o acesso ao manguezal e o conhecimento sobre como encontrar as tocas dos caranguejos, e daí como coletá-los. A coleta manual, em comparação com a redinha, requer um conhecimento mais refinado sobre, por exemplo, a estimativa do tamanho do caranguejo.

Por mais simples que seja, a atividade de coleta dos mariscos implica a prática diária de conhecimentos corporais refinados. As formas costumeiras de mariscagem 
envolvem por exemplo, seja no caso de coleta manual, seja com uso de colher, movimentos sutis com as mãos para avaliar o tamanho das conchas coletadas. Com isso, marisqueiras mais experientes coletam muito mais rápido que iniciantes. É preciso também adquirir resistência ao sol inclemente e à situação de semi-imersão diária. No caso do uso de novas técnicas mais agressivas, como a utilização de grades ou enxadas, simplificam-se os conhecimentos necessários para a coleta. Para além disso, as marisqueiras necessitam coordenar de maneira adequada o trabalho de coleta, de processamento e os demais afazeres domésticos que recaem sobre elas ${ }^{8}$.

O mesmo se dá para os pescadores de peixes e camarões, que precisam coordenar o tipo de malha correto para o tipo de peixe, ter habilidade no movimento de esticar e recolher as redes, de onde armá-las, além do paciente trabalho, em casa, de recuperação das redes danificadas. No mar de dentro, é fundamental a localização das pedras, croas e outros os pontos de pesca.

Para os pescadores embarcados na pesca de lagosta de alto mar, habilidades de localização também são fundamentais. A maneira tradicional de localização no alto mar por pescadores artesanais é a marcação, ou seja, a triangulação de marcas fixas em terra, bastante usada na região. Cada vez mais se utiliza o posicionamento por satélites (GPS). O princípio do GPS, entretanto, é em linhas gerais o mesmo da marcação. São muito importantes também para os lagosteiros o conhecimento dos ambiente do fundo do mar e os hábitos das lagostas, em especial nas técnicas ilegais de mergulho, seja com compressor, seja no peito (em apnéia). Nestas, um erro pode custar a vida do pescador.

Assim, diferentes pescarias produzem diferentes pescadores (Sautcuhk, 2007), e, mais do que isso, as diversas modalidades de relações pescador-pescado-pescaria produzem diferentes habilidades, diferentes malhas de relações, diferentes movimentos no estuário, diferentes formas de habitar (Ingold, 2000;2011). É no entrelaçamento destas diferentes relações de movimento que se conforma o que chamamos aqui da paisagem dos pescadores artesanais, esse entrelaçamento de malhas experienciais que compomos etnograficamente.

\footnotetext{
${ }^{8}$ Uma das principais reivindicações do movimento dos pescadores em favor das marisqueiras é o reconhecimento dos problemas de saúde relacionados à atividade, em especial o que os médicos chamam de lesão por esforço repetido (LER).
} 


\section{O liso e o estriado}

"É um espaço liso que é capturado, envolvido, por um espaço estriado, ou é um espaço estriado que se dissolve num espaço liso, que permite que se desenvolva um espaço liso?(Deleuze e Guatarrí, 2002[1980]:180)

Descrevemos acima uma paisagem produzida pela pesca artesanal. É uma paisagem que implica fluidez, deslocamento e experiência, remetendo à noção de espaço liso, ao invés do esquadrinhamento, o atrito e a planificação correspondentes ao espaço estriado (Deleuze e Guatarrí, 2002 [1980]). No espaço liso o que valem são direções e percursos, ao invés dos vetores e coordenadas do espaço estriado.

O espaço liso da pesca artesanal contém em si devires de seu oposto, o estriamento. Mas são estriamentos momentâneos, as pescarias: a interceptação dos peixes pelas redes que se interpõem no rio o no mar; os sulcos causados pelas mãos e colheres na coleta do marisco-pedra, e assim por diante. São estriamentos contidos e subordinados a uma malha que conforma um espaço liso.

Para compormos uma paisagem do estuário do rio Goiana, necessitamos, entretanto, nos debruçarmos sobre outras formas de estriamento, aquelas que se superpõem, contaminam e destroem a propriedade lisa da malha de relações da pesca artesanal.

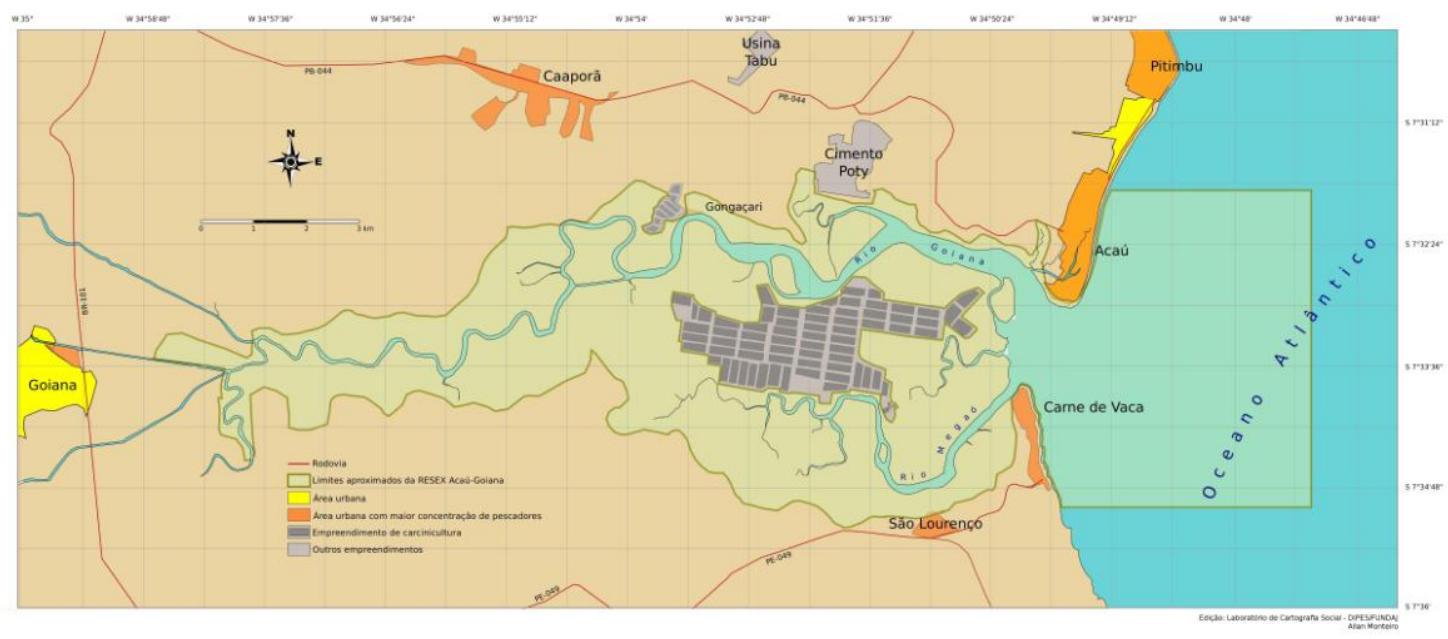

Figura 1: Estuário do Rio Goiana 
Observando a Figura 1, mapa construído sobre uma imagem de satélite do estuário do rio Goiana, percebemos, em cinza, dois empreendimentos de carcinicultura, com séries de retângulos justapostos, que correspondem a tanques para criação de camarão, que substituíram a vegetação nativa anteriormente presente, numa paisagem que permitia livre circulação no estuário. Assim como estes empreendimentos, a indústria de cimento que beira o manguezal, que substituiu sítios com lavouras e pomares, tornou-se área de acesso restrito, com o estabelecimento de estruturas planejadas e duradouras, destoantes da vegetação do manguezal, que constituem espaços estriados deliberadamente desconectados da malha da pesca artesanal. São polígonos, não percursos.

Este estriamento na paisagem interrompe ou dificulta os fluxos preexistentes. Interrompe os percursos dos pescadores, impede-lhes o acesso a certas áreas. A maior área de carcinicultura presente na imagem é narrada no passado pelos pescadores como uma ilha plena de floresta, usada para diversos fins extrativistas e como acesso ao lado oposto do manguezal.

Paradoxalmente, tais estriamentos produzem novos devires lisos, estes subordinados aos polígonos estriados. São eles fluxos de poluentes químicos ou biológicos, que se misturam e se dissolvem no espaço liso. Os pescadores narram episódios de mortalidade de pescados do estuário pela lavagem química dos tanques de camarão; substituição de espécies nativas de camarão por espécies exóticas criadas nos tanques; mortalidade de vegetação de mangue pelo impacto da fuligem da fábrica de cimento.

\section{Reserva extrativista}

Observando-se novamente a Figura 1, vemos uma área em verde, que tem contorno irregular sobre a porção continental do mapa. Ela segue da área próxima ao centro urbano de Goiana e se estende ao mar, adquirindo sobre o oceano um formato quadrado. Consultando a legenda, vemos que trata-se dos contornos da Reserva Extrativista Acaú-Goiana, uma unidade de conservação ambiental que prevê sua conservação e uso pelas populações tradicionais que a utilizam costumeiramente.

A Resex Acaú-Goiana foi criada pelo Governo Federal por solicitação dos pescadores, em 2007, após sua ampla mobilização, com apoio do Conselho Pastoral dos Pescadores, de pesquisadores de universidades e de técnicos do Ministério do Meio 
Ambiente. Posicionavam-se publicamente contrários à criação da Resex muitos políticos ligados às prefeituras dos municípios envolvidos, empresários da cana-deaçúcar e, em especial, o Governo do Estado de Pernambuco, que, além de atender às pressões dos empresário canavieiros, tinha planos de instalar uma grande infra-estrutura industrial no entorno do estuário do rio Goiana (Silveira et. al, 2011).

Os limites da Reserva foram traçados para acompanhar, em terra, o exato limite da ocorrência de vegetação de manguezal. No mar, espaço liso por excelência, elegeu-se uma área de contornos quadrados, no sentido de contemplar de forma genérica a pesca no mar.: o mar, espaço liso por excelência, pareceu permitir apenas um rascunho de esquadrinhamento. Com esses limites, ficaram incluídos na reserva as áreas de pesca, mas não as áreas de vida dos pescadores. As moradias, por exemplo, ficam fora da Resex.

A constituição de uma reserva extrativista para usos tradicionais permite, dentro de seu polígono, a persistência da paisagem-fluxo da pesca artesanal. Ou seja, a constituição desta modalidade de estriamento do espaço permite que ela contenha, em si, um espaço liso. Isso não parece, entretanto, garantir por si a manutenção deste espaço liso. Há estriamentos de espaços adjacentes, que destroem e contaminam malha-espaço liso dos pescadores.

Tratamos acima a poluição que afeta o rio Goiana como potências lisas que derivam de uma paisagem estriada e que contaminam os espaços lisos dos pescadores, pescados e pescarias. A paisagem do entorno do rio Goiana apresenta um estriamento já centenário, que consiste na substituição das florestas (espaço liso) por monocultura de cana-de-açúcar na porção litorânea de Pernambuco (que ainda hoje é chamada de Zona da Mata). Assim, a monocultura da cana já trazia há muito este tipo de relação negativa com a pesca artesanal, como mostra este fragmento de Nordeste de Gilberto Freyre:

\footnotetext{
Na semana do Natal de 1936, o rio Goiana, em Pernambuco, recebeu tanta calda que a quantidade de peixe podre foi enorme. Parecia uma praga do Velho Testamento. Os peixes mais finos fedendo de podres, ao lado dos mais plebeus. O cheiro de peixe podre misturando-se ao de fruta podre, das margens sujas dos rios. Quase não há um rio do Nordeste do canavial que alguma usina de ricaço não tenha degradado em mictório. [...] As moças e os meninos já não tomam banho de rio: só banho de mar. Só os moleques e os cavalos se lavam hoje na água suja dos rios. (Freyre, 1989 [1951]:. 83).
}

Hoje a poluição das usinas não ocorre de maneira tão escandalosa como no passado, mas os pescadores ainda denunciam despejo da calda, ou vinhoto, um subproduto da industrialização da cana-de-açúcar, in natura nos rios. Denunciam 
também a contaminação do rio pelo vinhoto que hoje é usado para adubação da lavoura, já que os canaviais avançam até a margem dos rios.

Atualmente, entretanto, há novos estriamentos que produzem contaminação do rio Goiana. Os fluxos socioecológicos obviamente não respeitam os limites do manguezal ou da reserva extrativista. Assim, o que ocorre no estuário está em ampla comunicação com o que ocorre em extensões espaciais adjacentes, e mesmo remotas, que se conectam com ele. Assim, a urbanização produz esgoto, e os matadouros, tanques de criação de camarão e indústrias derramam seus poluentes no rio.

A partir de 2010 iniciaram-se grandes investimentos privados ao longo dos pouco mais de 180 quilômetros do litoral pernambucano, cuja parte central já é ocupada pela massa urbana da Região Metropolitana do Recife. Tais empreendimentos são consequência de uma estratégia do Governo do Estado para atrair investimentos industriais a Pernambuco. Na região do estuário do rio Goiana, iniciaram-se durante a pesquisa as obras de um Pólo Farmacoquímico de Hemoderivados; anunciava-se uma fábrica de automóveis, um porto no estuário vizinho, e um aeroporto.

A influência, no polígono da Resex, do que lhe é presumivelmente externo, é tratada na legislação das unidades de conservação com a designação de zona de amortecimento, que é, no final das contas, um outro polígono que envolve o polígono da Resex, de área definida no documento chamado plano de manejo. Legalmente, os empreendimentos a serem instalados na zona de amortecimento devem passar por aprovação da gestão da Resex, que inclui um Conselho Deliberativo formado por maioria de pescadores e uma equipe técnica de gestão ligadas ao Ministério do Meio Ambiente, com uma chefia.

$\mathrm{Na}$ prática, essa estrutura formal funciona (ou não funciona) de maneiras muito variadas. Não trataremos deste ponto aqui (ver Silveira et al, 2011), indicando apenas que o processo de ordenamento pelo Estado dos usos da Resex pode trazer outros devires de estriamento. O que nos interessa é que, na conjuntura política em que escrevemos este artigo, em que há investimentos vultuosos em grandes obras e empreendimentos industriais em detrimento às políticas ambientais arduamente instauradas em anos anteriores, é muito difícil que a gestão da Reserva Extrativista consiga ter ingerência sobre empreendimentos na zona de amortecimento.

Acompanhamos esta tensão já em 2010, quando, após três anos de funcionamento, a Resex teve uma chefia, mas não foi possível nem aos pescadores, nem ao órgão ambiental fazer qualquer negociação com o Exército para impedir que a construção de 
uma ponte nas obras de duplicação da estrada BR 101, que corta o Rio Goiana na altura de Baldo do Rio, não assoreasse o rio, impedindo, entre outras coisas, o acesso dos pescadores do centro urbano ao estuário. Além disso, até 2012 os técnicos de gestão da Reserva não haviam recebido qualquer informação verossímil sobre os possíveis impactos sobre o estuário do Pólo Farmacoquímico e da fábrica de automóveis. Juntamse a estas suspeitas as notícias de que uma outra Reserva Extrativista litorânea, a de Iguape, na Bahia, terá sua área reduzida face a instauração de empreendimentos petrolíferos.

\section{Considerações Finais}

Indicamos aqui a existência de movimentos conformadores de uma malha de relações que consiste na paisagem da pesca artesanal no estuário do rio Goiana. Assim, a paisagem dos pescadores estuarinos no Rio Goiana é reconhecida a partir de suas práticas de conhecimento, que são inscritas espacialmente a partir de suas movimentações no estuário. É uma paisagem múltipla, por conter múltiplas formas de relações pescador-pescaria-pescado.

Caracterizamos portanto essa paisagem como próxima à noção deleuziana de espaço liso, e caracterizamos os efeitos de processos de estriamento deste espaço na destruição nesta paisagem. Indicamos ainda a produção de um estriamento específico no espaço, a Reserva Extrativista Acaú-Goiana, como uma forma de conter dentro de si a paisagem lisa da pesca artesanal, percebendo os limites deste tipo de estratégia.

Nestas considerações finais, trazemos um trecho do documento base para a campanha por regularização dos territórios pesqueiros, mobilização que praticamente fez ressurgir um movimento organizado de pescadores e pescadoras artesanais, em âmbito nacional, em 2009.

O direito de permanência [dos pescadores] nos territórios tradicionalmente pesqueiros são negados e estes são considerados espaços vazios, que tem sido tomado pelos grandes empreendimentos empresariais, latifúndios e especuladores de terras, turismo empresarial, implantação de parques aquiícolas, construção de grandes barragens, etc. A luta pela implantação de Unidades de Conservação Sustentáveis (UCs), como as Reservas Extrativistas (RESEX), são instrumentos importantes para manutenção da ocupação tradicional, ordenamento da pesca e a manutenção da identidade pesqueira. Mas, ainda não é suficiente para garantir os territórios como espaço de direito." (Movimento dos Pescadores e Pescadoras Artesanais, 2009, grifos nossos). 
As paisagens (lisas) da pesca artesanal são, como indica o documento, tomadas como espaços vazios, disponíveis ao estriamento dos grandes empreendimentos. As reservas extrativistas são consideradas importantes para estancar este estriamento em algumas destas paisagens, mas não suficientes. No período em que este artigo é escrito, o Movimento dos Pescadores e Pescadoras Artesanais, bastante articulado no Nordeste, e seus assessores e apoiadores, realizavam um esforço de reunião de assinaturas para um Projeto de Lei de iniciativa popular que propõe a regularização (ou seja, o reconhecimento fundiário) dos territórios pesqueiros. Esse projeto continua operando na linguagem da delimitação dos polígonos, aquela do ordenamento territorial que o Estado brasileiro é capaz de assimilar, mas tem nuances que tornam elásticas as determinações e usos possíveis destes polígonos.

Produzir polígonos geograficamente delimitados como zonas livres de estriamento, dentro dos quais os espaços lisos podem ter existência, tem sido uma estratégia pragmática no campo socioambiental. Povos tradicionais e movimentos sociais lutam pela criação de reservas extrativistas, territórios quilombolas e terras indígenas; ambientalistas menos preocupados com questões sociais militam pela criação de parques nacionais, reservas biológicas e outras unidade de conservação que pressupõem um espaço liso sem presença humana. O espaço liso como exceção tem sido o que é possível para os movimentos sociais negociar, a duras penas, com o Estado.

Desconfiamos, entretanto (e julgamos que o Movimento dos Pescadores e Pescadoras Artesanais compartilha desta desconfiança), de que a política dos polígonos como apropriação privada e ordenamento territorial, ou seja, a política do estriamento generalizado do espaço, deixa pouco lugar para a multiplicidade dos espaços lisos, ocupado por uma multiplicidade de formas de ser. A paisagem-fluxo da pesca artesanal nos parece sugerir, assim, como linhas de fuga, a urgência de uma ecologia política dos espaços lisos.

\section{Referências}

DELEUZE, G. e GUATARRÍ, F. Mil platôs: capitalismo e esquizofrenia, v.5. São Paulo: Editora 34, 2002 [1980].

FREYRE, G. Nordeste. 6 ${ }^{\mathrm{a}}$ ed., Rio de Janeiro: Record, 1989 [1951].

INGOLD, T. Being Alive. Nova York: Routledge, 2011. 
INGOLD, T. The perception of the environment. Nova York: Routledge, 2000.

IVO, C. T. C.; PEREIRA, J. A. Sinopse das principais observações sobre as lagostas Panulirus argus (Latreille) e Panulirus laevicauda (Latreille), capturadas em águas costeiras do Brasil, entre os estados do Amapá e do Espírito Santo. Boletim Técnico-Científico do Cepene Vol. 4, N. $1,1996$.

LAW, J.; MOL, A. (ed.). Complexities: social studies of knowledge practices. Durham e Londres: Duke University Press, 2002.

\section{MOVIMENTO DOS PESCADORES E PESCADORAS ARTESANAIS, 2009}

RAMALHO, C. Gestão ecológica enquanto conhecimento patrimonial dos pescadores artesanais: um estudo comparativo entre práticas pesqueiras estuarina e marítima em pernambuco. Relatório de pesquisa, Fundaj/Facepe/CNPq. Recife: 2012.

SAUTCHUK, Carlos Emanuel. $O$ arpão e o anzol: técnica e pessoa no estuário do amazonas (Vila Sucuriju, Amapá). Tese (Doutorado) - Curso de Antropologia, Departamento de Antropologia, Universidade de Brasília: Brasília, 2007.

SILVA-CAVALCANTI, J. S. Biologia e exploração da Anomalocardia brasileira por populações de ribeirinhos no estuário do Rio Goiana (PE-PB), Nordeste do Brasil. Tese de Doutorado em Oceanografia, Universidade Federal de Pernambuco. Recife, 2011.

SILVEIRA, P.C.B. . Híbridos na paisagem: uma etnografia de espaços de produção e de conservação. Ambiente e Sociedade , v. 12, p. 83-98, Campinas: 2009.

SILVEIRA, P. C. B. Conhecimentos científicos, conhecimentos locais e hibridismo: por uma etnografia simétrica da paisagem. R@U : Revista de Antropologia Social dos Alunos do PPGAS-UFSCAR, v. 3, p. 212-235, 2011.

SILVEIRA, P. C. B.; PEDROSA, B.M.; MELO, L.;ROSAS, J.C.; SANTOS, L.; OLIVEIRA FILHO, I. Reservas extrativistas e pesca artesanal:etnografia do campo socioambiental em Pernambuco. Relatório de pesquisa, Fundaj/Facepe. Recife: 2011.

Recebido em 20/09/2013

Aprovado em: 10/11/2013 